(C) Copyright 2019: Editum. Servicio de Publicaciones de la Universidad de Murcia. Murcia (Spain) ISSN print edition: 0212-9728. ISSN on line edition (http://revistas.um.es/analesps): 1695-2294.

On line edition License Creative Commons 4.0: BY-NC-ND

\title{
The revolving door to homelessness. The influence of health, alcohol consumption and stressful life events on the number of episodes of homelessness
}

\author{
Pablo Roca ${ }^{1}$, Sonia Panadero ${ }^{1}$, Sara Rodríguez-Moreno ${ }^{1}$, Rosa María Martín ${ }^{2}$, and José Juan Vázquez²* \\ 1 Universidad Complutense de Madrid (Spain) \\ 2 Universidad de Alcalá (Spain)
}

\begin{abstract}
Título: "Puerta giratoria" a la situación sin hogar. Influencia de la salud, consumo de alcohol y padecimiento de sucesos vitales estresantes en el número de episodios en la situación sin hogar.

Resumen: Objetivos: Analizar la incidencia de diferentes variables en el padecimiento de reiterados episodios en la situación sin hogar. Método: El trabajo se realizó a partir de los datos obtenidos de una muestra representativa de las personas en situación sin hogar en Madrid (España) $(n=188)$. Re sultados: El padecimiento de una enfermedad grave o crónica ejerce un efecto en la "puerta giratoria" a la situación sin hogar mediado por una percepción subjetiva muy negativa de la propia salud que, a su vez, se encuentra mediada por el padecimiento de alguna discapacidad. El consumo excesivo de alcohol ejerce un efecto en la "puerta giratoria" a la situación sin hogar mediado por el acceso a tratamiento por problemas derivados de dicho consumo. Padecer una enfermedad grave o crónica correlaciona con tener o haber tenido problemas derivados de un consumo excesivo de alcohol. El padecimiento de múltiples sucesos vitales estresantes ejerce un efecto directo en la "puerta giratoria" a la situación sin hogar. Conclusiones: Para prevenir la "puerta giratoria" a la situación sin hogar hay que eliminar las barreras que dificultan el acceso a los recursos normalizados de salud a las personas en exclusión social, a la vez que implementar programas continuados de apoyo para las personas sin hogar o en riesgo que incluyan prioritariamente cuestiones de salud.

Palabras clave: Personas en situación sin hogar, Cronicidad en la situación sin hogar; Salud; Consumo de alcohol; Sucesos vitales estresantes.
\end{abstract}

\section{Introduction}

Homelessness is a social problem with enormous significance for public health (Caton et al., 2005). It is estimated that around 30,000 people are homeless in Spain. In Madrid, the capital of Spain, the City Council estimated the number of homeless people at 1,905 in 2014. Of these, 1,141 were sleeping in the network of municipal shelters or other care centres, and 764 were spending the night in the street or unsuitable places (Vázquez, Panadero, \& Zúñiga, 2017a, 2017b, 2018).

According to the U.S. Department of Housing and Urban Development's (HUD) definition, a chronically homeless individual is someone who has experienced homelessness for a year or longer, or who has experienced at least four episodes of homelessness in the last three years (totalling 12 months), and who has a disability (U.S. HUD, 2015).

Suffering from multiple episodes of homelessness after having gained access to independent housing (the revolving door to homelessness) is an understudied issue that is rarely

* Correspondence address [Dirección para correspondencia]:

José Juan Vázquez. Universidad de Alcalá. Aulario María de Guzmán. C/ San Cirilo, s/n. 28801 Alcalá de Henares, Madrid (Spain).

E-mail: ji.vazquez@uah.es

(Article received: 23-06-2017; revised: 14-12-2017; accepted: 01-11-2018)
Abstract: Objectives:- To analyse the impact of different variables on repeated episodes of homelessness. Method: The study was conducted based on data obtained from a representative sample of homeless people in $\mathrm{Ma}$ drid (Spain) $(n=188)$. Results: Suffering from a serious or chronic illness has an effect on the revolving door to homelessness, which is mediated by a highly negative subjective perception of the individual's own health, which is in turn mediated by suffering from a disability. Excessive alcohol consumption has an effect on the revolving door to homelessness, mediated by access to treatment for problems caused by alcohol consumption. Suffering from a serious or chronic illness correlates with having problems caused by excessive alcohol consumption. Experiencing multiple stressful life events has a direct effect on the revolving door to homelessness. Conclusions: To prevent the revolving door to homelessness, it is necessary to remove the barriers that hinder access to normal health resources which are experienced by people suffering from social exclusion, while implementing ongoing support programmes for homeless people or those at risk of homelessness, which primarily deal with health issues.

Key words: Homeless people; Chronically homeless; Health; Alcohol consumption; Stressful life events. addressed in the literature (Ringwalt, Greene, Robertson, \& McPheeters, 1998). In Madrid, 28\% of homeless people have been homeless between two and five times, and 14\% have been harmless more than five times (Panadero \& Vázquez, 2016). The phenomenon of the revolving door to homelessness warrants special attention, since it is a relevant factor in the persistence of the problem of homelessness, and has a significant effect on the sufferer's quality of life. Kuhn and Culhane (1998) found three distinct patterns of shelter stays among the homeless population of single adults, which they identified as 'transitional,' 'episodic', or 'chronic'. The 'episodic' homeless group had the most episodes of homelessness. Despite being younger than the chronic homeless, the episodic homeless group had similar physical and mental health problems to the chronic group, including substance abuse.

In addition to the time spent homeless and the number of episodes, according to the definition of U.S. HUD (2015), for a person to be considered chronically homeless they must be a "homeless individual with a disability", i.e. they must be suffering from a physical or mental condition that limits a person's movements, senses, or activities. These three aspects (time spent homeless, number of episodes of homelessness and disability) are to a large extent related to each other. Health problems appear to be particularly relevant factors in processes of returning to homelessness after 
having gained access to independent housing (Aubry, Klodawsky, \& Coulombe, 2012; Kim, Kertesz, Horton, Tibbetts, \& Samet, 2006; Panadero \& Muñoz, 2014). Similarly, remaining homeless poses a threat to health (Ropers \& Boyer, 1987; Panadero \& Muñoz, 2014) by aggravating existing illnesses, preventing recovery from those illnesses and causing new illnesses (Schanzer, Dominguez, Shrout, \& Caton, 2007). Individuals who are chronically homeless and disabled are at greater risk of negative health consequences due to an increased prevalence of mental health issues, substance abuse disorders, and a higher level of disconnection from preventative medical care (Parker, 2010). In this regard, disability appears to be related to chronic homelessness, so that homeless people with disabilities remain homeless for longer periods of time (Panadero \& Muñoz, 2014; Parker, 2010).

Aubry et al. (2012) note that among the various health problems, people with substance abuse have the greatest difficulties with overcoming their homelessness and achieving housing stability. Excessive alcohol consumption has been identified as one of the most important risk factors in individuals becoming and remaining homeless (Caton et al., 2005; Greenberg \& Rosenheck, 2009; Suarez, Berrios, Bonilla, \& Vázquez, 2018). The prevalence of alcohol dependence among homeless people has been placed at around 37.9\% (Fazel, Khosla, Doll, \& Geddes, 2008), while among chronically homeless people the prevalence of alcohol dependence is even greater (Kuhn \& Culhane, 1998). In Madrid, more than half of the homeless people reported having consumed too much alcohol at some point in their life, and the percentage reached 59\% among homeless men (Panadero, Vázquez, \& Martín, 2017).

Meanwhile, experiencing multiple stressful life events is also a relevant factor in vulnerability to becoming and remaining homeless, while homelessness itself is a factor in vulnerability to experiencing a larger number of stressful life events (Dworsky, Napolitano, \& Courtney, 2013; Muñoz, Panadero, Pérez-Santos, \& Quiroga, 2005; Muñoz, Vázquez, Bermejo, \& Vázquez, 1999; Vázquez, Panadero, Martín \& Díaz-Pescador, 2015).

This paper aims to analyse in overall terms the factors affecting the probability of suffering from more episodes of homelessness, and proposes an explanatory model that integrates the combined influence of health variables, alcohol problems and experiencing stressful life events on the number of episodes of homelessness.

\section{Method}

The research took place based on data provided by a representative sample of homeless people in Madrid (Spain) $(n=188)$, of legal age $=47.57$ years, $S D=12.172)$, consisting mostly of men $(84.0 \%$ men, $16.0 \%$ women), and mostly of Spanish nationality $(71.8 \%$ were Spanish and $28.2 \%$ were foreigners). Homeless people were considered to be those who had spent the night before the interview in a shelter or other facility for homeless people, on the street or in other places not initially designed for sleeping: abandoned buildings, basements, metro stations, etc. The sample size was determined from the available data on the total number of homeless people in Madrid. A strategy of random sampling in the street and in all housing resources for the homeless in Madrid was designed, with the number of participants selected in proportion to the capacity of each service and the number of homeless people spending the night on the street in Madrid.

A structured interview was used to collect the information (Panadero \& Vázquez, 2016). The informed consent of the participants was requested after explaining the aims of the investigation and the management of the data, ensuring the anonymity of those who took part in the study.

\section{Data analysis}

One hundred eighty six participants of the 188 in the initial sample were selected, and the information for two participants who did not respond to the dependent variable "number of episodes of homelessness" was deleted. The method proposed by Hair, Black, Babin and Anderson (2014) was used to analyse the missing values. A diagnosis of the randomness pattern of the missing values (Little \& Rubin, 1990) was performed by Little's MCAR test $\left(\chi^{2}=66.85, p<.05\right)$. In order to avoid generating biased estimates, the multiple imputation method (Tabachnick \& Fidell, 2012) was used for the treatment of the missing data using the SPSS program. A sensitivity analysis was subsequently performed, which ruled out the risk of making biased estimates when using multiple imputation.

A Path Analysis was then performed using Structural Equation Modeling (SEM), estimated using Maximum Likelihood methods by means of the AMOS statistical program. Various nested models were generated to evaluate which one provided the best fit (MacCallum, 1995). The goodness of fit of the respective models was evaluated using multiple indices in the following procedure: (a) examination of the factorial loads of the different exogenous variables and their predictive power with respect to the endogenous variable, which established $p<.05$ as adequate value (Stevens, 2009); (b) examination of the value of $\chi^{2}$ to assess the overall fit of the model, taking values of $p>.05$ as indicating a good fit (Kline, 2005); (c) examination of various indices to assess the absolute fit (GFI and RMSA) and the incremental fit (AGFI, TLI, CFI and NFI), with scores above .95 considered as showing a good fit of the model (Hu \& Bentler, 1999); (d) examination of the fit of the model using the Root Mean Square Error of Approximation (RMSEA), with scores of .60 or lower considered to be a good fit (Hu \& Bentler, 1999); and (e) evaluation of whether the introduction of the parameters improved the fit of nested models using the statistic $\Delta \chi^{2}$ (Kline, 2005). Assumptions of univariate normality and assumptions of multivariate normality were found not to fit the global model. However, in anticipation of the possible failure the assumption of normality, the analyses used the 
procedure of maximum likelihood estimation, which is known to be the most demanding and robust in terms of failure the assumption of normality (Kline, 2005).

\section{Results}

Figure 1 shows the different structural models evaluated.


Model 3 (Competing model)

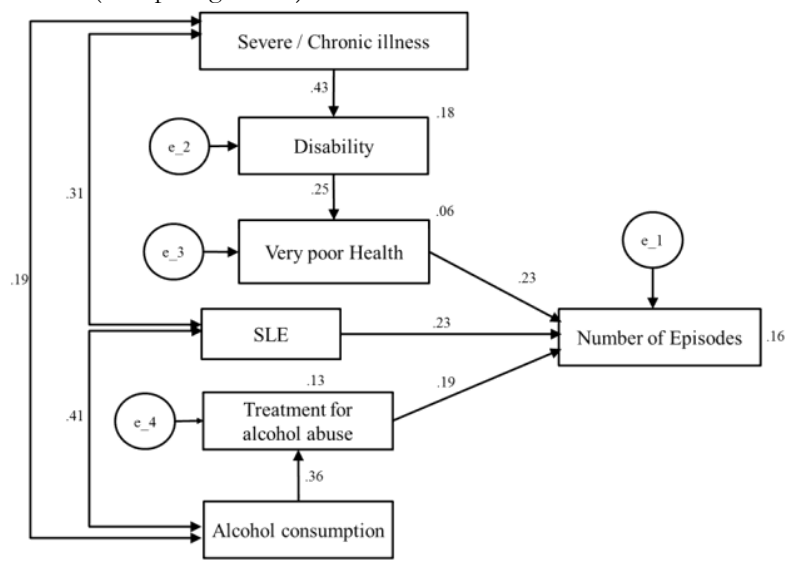

Figure 1. Structural models tested for variable "Number of episodes of homelessness".

Model 1 shows the direct influence of "Suffering from a serious or chronic illness" (Severe/chronic illness), "Having or having had problems due to excessive alcohol consumption" (Alcohol consumption) and having experienced multiple stressful life events - "Number of stressful life events experienced throughout his/her life" (SLE) - on the "Number of episodes of homelessness" (Number of episodes). Model 2 shows the influence on the "Number of episodes of homelessness" (Number of episodes) of "Considering his/her state of health to be very poor" (Very poor health), and not of suffering from a serious or chronic illness (Model 1) - and "Receiving or having received treatment for problems related to alcohol consumption" (Treatment for alcohol abuse) - and not alcohol consumption (Model 1). Finally, Model 3 includes health variables ("Suffering from a serious or chronic illness" (Severe/chronic illness) and "Having a disability" (Disability)) and "Having or having had problems related to excessive alcohol consumption" (Alcohol consuption), and hypothesises that these variables exert an indirect influence on the number of episodes of homelessness mediated by "Considering his/her state of health to be very poor" (Very poor health) in the former case and "Receiving or having received treatment for problems related to alcohol consumption" (Treatment for alcohol abuse) in the latter case. The variables that have a mediated effect on the number of episodes of homelessness were introduced in an attempt to clarify the relationship between health and alcohol consumption and the number of episodes of homelessness. "Suffering from a serious or chronic illness", "Suffering from some form of disability" and "Having or having had problems due to excessive alcohol consumption" were found to have an influence on the number of episodes of homelessness through partial mediation. Both Model 1 and Model 3 show covariations between the "Number of stressful life events experienced throughout his/her life," "Suffering from a serious or chronic illness" and "Having or having had problems due to excessive alcohol consumption" - a question that would arise from the last two variables being included in the list of possible stressful life events experienced.

Table 1 contains the values of the main goodness of fit indices of the nested models. The results of the various fit indices show that Model 1 (the base model) does not show a adequately fit $\left(\chi^{2}(1)=6.98 p>.050\right)$. However, replacing the variables "Suffering from a serious or chronic illness" with "Considering his/her state of health to be very poor" and "Having or having had problems related to excessive alcohol consumption" with "Receiving or having received treatment for problems related to alcohol consumption" improves the fit in Model $2\left(\chi^{2}(3)=8.64, p>.050\right)$, and only the variable "Number of stressful life events experienced throughout his/her life" is retained from Model 1. In addition, when the increase in Chi-square $\left(\Delta \chi^{2}\right)$ is estimated, these changes are found to generate significant improvements in Model 2 by comparison with Model $1\left(\Delta \chi^{2}(2)=6.98-8.64=-1.66, p=\right.$ $.000)$. Finally, the introduction of indirect effects in Model 3 also shows an adequate fit $\left(\chi^{2}(12)=10.43, p>.050\right)$, so that the addition of these variables, which have an effect mediated by the number of episodes of homelessness, significantly improves the fit of Model 3 in comparison with Model 2 $\left(\Delta \chi^{2}(9)=8.64-10.43=-1.79, p=.000\right)$.

Considering a) the rates of goodness of fit in Model 3 ; b) the significant indirect (mediated) effect of the three varia- 
bles introduced (suffering from a serious or chronic illness, having a disability and having or having had problems with excessive alcohol consumption) on the number of episodes (Table 2); c) the significant improvement in the fit in Model
3 compared to the two previous models, respecting the principle of parsimony; it can be concluded that Model 3 is the most appropriate for predicting the "Number of episodes of homelessness".

Table 1. Goodness of Fit Indices for the nested models of the variable "Number of episodes of homelessness".

\begin{tabular}{|c|c|c|c|c|}
\hline \multirow{2}{*}{ GOODNESS OF FIT INDICES } & & \multirow{2}{*}{$\frac{\text { Base model }}{\text { Model } 1}$} & \multicolumn{2}{|c|}{ Competing Models } \\
\hline & & & Model 2 & Model 3 \\
\hline \multirow{6}{*}{ Absolute Adjustment Measures } & Chi-square $\left(\chi^{2}\right)$ & 6.98 & 8.64 & 10.43 \\
\hline & Degrees of freedom (df) & 1 & 3 & 12 \\
\hline & Significance ( $\mathrm{p}$ value) & 0.008 & 0.034 & 0.578 \\
\hline & $\chi^{2} / \mathrm{df}$ & 6.982 & 2.882 & 0.869 \\
\hline & Goodness of Fit Index (GFI) & 0.982 & 0.977 & 0.985 \\
\hline & Root Mean Square Error of Approximation (RMSEA) & 0.180 & 0.101 & 0.001 \\
\hline \multirow{4}{*}{ Incremental Adjustment Measures } & Adjusted Goodness of Fit Index (AGFI) & 0.818 & 0.925 & 0.964 \\
\hline & Tucker Lewis Index (TLI) & 0.490 & 0.693 & 1 \\
\hline & Confirmatory Fit Index (CFI) & 0.915 & 0.846 & 1 \\
\hline & Normed Fit Index (NFI) & 0.909 & 0.798 & 0.939 \\
\hline \multirow{4}{*}{ Parsimony Adjustment Measures } & Parsimonious Normed Fit Index (PNFI) & 0.151 & 0.399 & 0.537 \\
\hline & Parsimonious Goodness of Fit Index (PGFI) & 0.153 & 0.423 & 0.571 \\
\hline & Akaike Information Criterion (AIC) & 24.982 & 22.645 & 42.433 \\
\hline & Bayes Information Criterion (BIC) & 54.014 & 45.225 & 94.045 \\
\hline
\end{tabular}

Table 2. Factor loadings and significance levels of the variables included in the different structural models.

\begin{tabular}{|c|c|c|c|c|}
\hline \multicolumn{3}{|c|}{ CAUSAL RELATIONSHIPS } & Standardized regression weights & \multirow[t]{2}{*}{$p$ value } \\
\hline \multicolumn{4}{|c|}{ MODEL 1 (BASE MODEL) } & \\
\hline SLE & $\rightarrow$ & Number of episodes & .18 & .019 \\
\hline Alcohol consuption & $\rightarrow$ & Number of episodes & .14 & .065 \\
\hline Severe / chronic illness & $\rightarrow$ & Number of episodes & .14 & .051 \\
\hline SLE & $\leftrightarrow$ & Alcohol consuption & .37 & .000 \\
\hline SLE & $\leftrightarrow$ & Severe / chronic illness & .24 & .000 \\
\hline \multicolumn{5}{|c|}{ MODEL 2 (COMPETING MODEL) } \\
\hline SLE & $\rightarrow$ & Number of episodes & .23 & .000 \\
\hline Very poor health & $\rightarrow$ & Number of episodes & .24 & .000 \\
\hline Treatment for alcohol abuse & $\rightarrow$ & Number of episodes & .19 & .005 \\
\hline \multicolumn{5}{|c|}{ MODEL 3 (COMPETING MODEL) } \\
\hline SLE & $\rightarrow$ & Number of episodes & .23 & .000 \\
\hline Very poor health & $\rightarrow$ & Number of episodes & .23 & .000 \\
\hline Treatment for alcohol abuse & $\rightarrow$ & Number of episodes & .19 & .006 \\
\hline Severe / chronic illness & $\rightarrow$ & Disability & .43 & .000 \\
\hline Disability & $\rightarrow$ & Very poor health & .25 & .000 \\
\hline Alcohol consuption & $\rightarrow$ & Treatment for alcohol abuse & .36 & .000 \\
\hline Severe / chronic illness & $\rightarrow$ & Number of episodes (indirect) & .03 & .003 \\
\hline Disability & $\rightarrow$ & Number of episodes (indirect) & .06 & .003 \\
\hline Alcohol consuption & $\rightarrow$ & Number of episodes (indirect) & .07 & .012 \\
\hline Alcohol consuption & $\leftrightarrow$ & Severe / chronic illness & .05 & .010 \\
\hline SLE & $\leftrightarrow$ & Severe / chronic illness & .50 & .000 \\
\hline SLE & $\leftrightarrow$ & Alcohol consuption & .67 & .000 \\
\hline
\end{tabular}

Alcohol consuption = "Having or having had problems due to excessive alcohol consumption"

Severe / chronic illness = "Suffering from a serious or chronic illness"

SLE $=$ "Number of stressful life events experienced throughout his/her life"

Disability = "Having a disability"

Very poor health $=$ "Considering his/her state of health to be very poor"

Treatment for alcohol abuse $=$ "Receiving or having received treatment for problems related to alcohol consumption"

Number of episodes= "Number of episodes of homelessness" 
The results in Table 2 show that all the standardised direct effects of Model 3 are statistically significant, taking average values (Kline, 2005). Similarly, the indirect effects of suffering from a serious or chronic illness and suffering from some form of disability (mediated by the individual considering their general state of health to be very poor) and having or having had problems related to excessive alcohol consumption (mediated by receiving or having received treatment for problems related to alcohol consumption) are statistically significant. The final model explains a $16 \%$ of variance in the "Number of Episodes of Homelessness".

\section{Discussion}

Many circumstances may lead individuals to suffer from repeated episodes of homelessness after gaining access to independent housing, although issues related to health, alcohol consumption and experiencing stressful life events appear to be particularly influential. This finding, reflected in the model proposed in this paper, is consistent with the scientific literature on the chronification and number of episodes of homelessness (Aubry et al., 2012; Caton et al., 2005; Dworsky et al., 2013; Greenberg \& Rosenheck, 2009; Kim et al., 2006; Muñoz et al., 2005; Panadero \& Muñoz, 2014; Parker, 2010).

The proposed model, which seeks to explain some individuals' repeated slide into homelessness, suggests that suffering from a chronic or serious illness has an effect on the revolving door to homelessness which is mediated by a very negative subjective perception of the individual's own health, which is in turn mediated by suffering from a disability. Homeless people with a serious illness and/or a disability may have a limited ability to function, which leads to increased care needs and greater dependence on others $(\mathrm{Pa}-$ nadero \& Muñoz, 2014; Parker, 2010). The low levels of social and family support available to homeless people hinder their access to the care required to deal with illness and disability, which increases their chances of repeatedly becoming homeless.

This model suggests that excessive alcohol consumption has an effect on the revolving door to homelessness, mediated by access to treatment for problems caused by that consumption. Relapses in consumption following therapeutic withdrawal could increase the number of episodes of homelessness. Unfortunately, in Madrid the percentage of homeless people who reported having alcohol problems appears to

\section{References}

Aubry, T., Klodawsky, F., \& Coulombe, D. (2012). Comparing the housing trajectories of different classes within a diverse homeless population. American Journal of Community Psychology, 49(1-2), 142-155. doi: 10.1007/s10464-011-9444-z.

Caton, C.L., Dominguez, B., Schanzer, B., Hasin, D.S., Shrout, P.E., Felix, A.,... Hsu, E. (2005). Risk factors for long-term homelessness: Findings from a longitudinal study of first-time homeless single adults. have increased over the last decade (Panadero \& Vázquez, 2016), and the number of accessible treatment programmes for this group is insufficient (Panadero et al., 2017).

Meanwhile, the model also suggests that experiencing multiple stressful life events has a direct effect on the revolving door to homelessness. According to the results reported by various authors (Dworsky et al., 2013; Muñoz et al., 2005), experiencing stressful life events is a vulnerability factor that facilitates becoming homeless, makes remaining homeless more likely, and impacts on the reiterated slide into homelessness after having gained access to independent housing. In addition, homelessness is itself a vulnerability factor for experiencing multiple stressful life events (Muñoz et al., 1999).

Finally, the model shows that having a serious or chronic illness is significantly correlated with having problems caused by excessive alcohol consumption. Excessive alcohol consumption affects health (Panadero et al., 2017; Suarez et al., 2018), and suffering from a serious or chronic illness may also lead to an increase in alcohol consumption among homeless people.

These results suggest some relevant public health measures for reducing the revolving door to homelessness. First, it is essential to remove barriers hindering access to standard health resources for those at risk of social exclusion. It is also necessary to design support programmes for homeless people or those at risk of becoming homeless which primarily include health issues. These programmes should be implemented on an ongoing and uninterrupted basis, and provide particular care for those suffering from serious or chronic health problems, disability and/or problems arising from substance abuse, who should be provided with access to conditions that permit proper treatment, convalescence and rehabilitation (e.g. access to housing, medication, an adequate diet, care, etc.). In the specific case of problems arising from excessive alcohol consumption - a particularly relevant factor in becoming homeless once again after having gained access independent housing - it is necessary to remove the significant difficulties that homeless people must face in order to access appropriate treatment and remain within treatment on a sustained basis (Panadero et al., 2016). Meanwhile, sustained long-term support interventions must facilitate prevention and address the multiple stressful life events to which homeless people are subject. These issues have been identified as an important vulnerability factor in the revolving door to homelessness.
American Journal of Public Health, 95, 1753-1759. doi: 10.2105/AJPH.2005.063321.

Dworsky, A., Napolitano, L., \& Courtney, M. (2013). Homelessness during the transition from foster care to adulthood. American Journal of Public Health, 103(S2), S318-S323. doi: 10.2105/AJPH.2013.301455

Fazel, S., Khosla, V., Doll, H., \& Geddes, J. (2008). The prevalence of mental disorders among homeless in western countries: Systemic review 
and meta-regression analysis. Plos Medicine, 5(12): e225. doi: 10.1371/journal.pmed.0050225

Greenberg, G.A. \& Rosenheck, R.A. (2009). Correlates of past homeless in the National Epidemiological Survey on Alcohol and Related Conditions. Administration and Policy in Mental Health and Mental Health Services Research, 37, 357-366. doi: 10.1007/s10488-009-0243-x

Kim, T.W., Kertesz, S.G., Horton, N.J., Tibbetts, N., \& Samet, J.H. (2006). Episodic homelessness and health care utilization in a prospective cohort of HIV-infected persons with alcohol problems. BMC Health Services Research, 6(1), 1. doi: 10.1186/1472-6963-6-19.

Kuhn, R., \& Culhane, D.P. (1998). Applying cluster analysis to test a typology of homelessness by pattern of shelter utilization: Results from the analysis of administrative data. American Journal of Community Psychology, 26(2), 207-232. doi: 10.1023/A:1022176402357.

Muñoz, M., Panadero, S., Santos, E.P., \& Quiroga, M.A. (2005). Role of stressful life events in homelessness: An intragroup analysis. American Journal of Community Psychology, 35(1-2), 35-47. doi: 10.1007/s10464-0051888-6.

Panadero, S. \& Muñoz, M. (2014). Salud, calidad de vida y consumo de sustancias en función del tiempo en situación sin hogar. Anales de Psicologia, 30(1), 70-77.

Panadero, S. \& Vázquez, J.J. (2016). En las fronteras de la ciudadanía. Situación de las personas sin hogar y en riesgo de exclusión social en Madrid. Alcalá de Henares: Universidad de Alcalá.

Panadero, S., Vázquez, J.J., \& Martín, R.M. (2017). Alcohol, poverty and social exclusion: Alcohol consumption among the homeless and those at risk of social exclusion in Madrid. Adicciones, 29(1), 33-36. doi: 10.20882/adicciones. 830

Ringwalt, C.L., Greene, J.M., Robertson, M., \& McPheeters, M. (1998). The prevalence of homelessness among adolescents in the United States.
American Journal of Public Health, 88(9), 1325-1329. doi: 10.2105/AJPH.88.9.1325

Ropers, R.H., \& Boyer, R. (1987). Perceived health status among the new urban homeless. Social Science \& Medicine, 24(8), 669-678. doi: 10.1016/0277-9536(87)90310-8.

Schanzer, B., Dominguez, B., Shrout, P.E., \& Caton, C.L. (2007). Homelessness, health status, and health care use. American Journal of Publi Health, 97(3), 464-469. doi: 10.2105/AJPH.2005.076190.

Suarez, A., Berrios, A., Bonilla, E., \& Vázquez, J.J. (2018). Homeless people in Nicaragua: A point-in-time count in León. Journal of International Development, 30(1), 155-158. doi: 10.1002/jid.3303.

U.S. Department of Housing and Urban Development (2015). Homeles Management Information System. Retrieved from https://www.hudexchange.info/hmis/.

Vázquez, J.J., Panadero, S., Martín, R.M., \& Díaz-Pescador, V. (2015). Access to new information and communication technologies among homeless people in Madrid (Spain). Journal of Community Psychology, 43(3), 338-347. doi: 10.1002/jcop.21682.

Vázquez, J.J., Panadero, S., \& Zúñiga, C. (2017a). Content and uniformity of stereotypes and meta-stereotypes of homeless people in Madric (Spain). Journal of Community Psycbology, 45(1), 128-137. doi: 10.1002/jcop. 21836.

Vázquez, J.J., Panadero, S., \& Zúñiga, C. (2017b). Actors, observers, and causal attributions of homelessness: Differences in attribution for the causes of homelessness among domiciled and homeless people in $\mathrm{Ma}$ drid, 87(1), 15-22. American Journal of Orthopsychiatry. doi: $10.1037 /$ ort 0000130 .

Vázquez, J.J., Panadero, S., \& Zúñiga, C. (2018). Attributions about homelessness in homeless and domiciled people in Madrid, Spain: «Why are they homeless people?». American Journal of Orthopsychiatry, 88(2), 236247. doi: $10.1037 /$ ort 0000246 